\title{
Knee arthrodesis as a salvage method for septic TKA failure
}

\author{
Traian Ciobanu*, loan Mihau Japie*, Octavian Nutiu*, Alexandru Papuc*, Dragos Radulescu**, \\ Radu Radulescu** \\ * Orthopaedics and Traumatology Department, Universitary Emegency Hospital Bucharest Romania \\ ** University of Medicine and Pharmacy "Carol Davila" Bucharest Romania
}

Correspondence to: Alexandru Papuc, MD, Orthopaedics and Traumatology Department, Universitary Emegency Hospital Bucharest, 169 Splaiul Independentei Street, code 050474, Bucharest, Romania Mobile phone: +40731328280, E-mail: alexandrumpapuc@gmail.com

\begin{abstract}
Periprosthetic joint infection is the most common reason for a failed TKA, with a septic TKA reported rate of 1 to $4 \%$ of primary TKA patients. Septic TKA has a various number of treatment options which include chronic-suppressive antibiotics, irrigation and debridement, single or staged revision arthroplasty. The goal is to eradicate the periprosthetic joint infection and reimplant a sterile and fully functional total knee prosthesis. In case the infection becomes uncontrollable, there is only one option to eradicate the infection: knee arthrodesis or above-knee amputation.

We report the case of a 63-year-old patient who in 2009 underwent TKA, the 1 year follow-up showed periprosthetic infection. At first stage, the prosthetic implants were removed and a solid cement spacer was shaped to occupy the remaining space. In 2011, after achieving complete clinical and biological remission of the infection, the cement spacer was removed and LCCK revision prosthesis was inserted.

In 2013 reinfection occurred leading to removal of the prosthetic implants and reinsertion of an antibiotic impregnated cement spacer.

Since the patient suffered significant bone loss and the local conditions were unfavorable, being prone to infection, there were 2 options to evaluate: knee arthrodesis or above knee amputation. We chose knee arthrodesis using llizarov external fixation technique.

Many surgical techniques are available to achieve knee arthrodesis: internal fixation with plates or intramedullary nails and external fixation. The llizarov method is a very effective technique that could be taken into consideration when knee arthrodesis is required.

Keywords: Knee arthrodesis; llizarov frame salvage method; Septic TKA
\end{abstract}

\section{Introduction}

The number of total knee arthroplasty operations has experienced a tremendous growth in the past years. The number of post operative complications, including infections and implant failures, has an increased growth as well.

Periprosthetic joint infection is the most common reason for a failed TKA, with a septic TKA reported rate of 1 to $4 \%$ of primary TKA patients.

SepticTKAhasavariousnumberoftreatment options which include chronic-suppressive antibiotics, irrigation and debridement, single or staged revision arthroplasty. The goal is to eradicate the periprosthetic joint infection and reimplant a sterile and fully functional total 
knee prosthesis.

In case the infection becomes uncontrollable, there is only one option to eradicate the infection: knee arthrodesis or above-knee amputation.

Knee arthrodesis is a widely performed surgical procedure which has defined indications [21,31,35,42]. It is the best choice for patients with recurring knee infections and extensive bone loss. The goal is to achieve a better functional outcome compared to an above-knee amputation and gain a pain-free and stable lower limb.

There are many surgical techniques that have been proposed for knee arthrodesis: internal osteosynthesis, intramedullary nailing and external fixation. We present a case study with knee arthrodesis performed in our institution using the llizarov method.

Table 1. Indications and contraindications for knee arthrodesis

\section{Contra-indications \\ Contralateral knee amputation \\ Contralateral knee/ hip arthrodesis \\ Degenerative changes in ipsilateral hip Severe degenerative spine osteoarthritis Life-threatening infection}

\section{Indications}

Quadriceps muscle deficit

Poor soft tissue coverage

Extensive bone loss

Recurring infections

Poliomyelitis sequelae

Charcot knee joint

\section{Methods}

We report the case of a 63-year-old patient who was admitted in our clinic in 2009 for bilateral knee arthrosis, pain predominant in the right knee, for which he underwent total right knee arthroplasty. Postoperative evolution was uneventful until the first year follow-up when periprosthetic infection with Klebsiella Pneumoniae and multi drug resistant Staphylococcus Aureus was detected (fig. 1). At first stage, the prosthetic implants were removed, accurate bone and soft tissue debridement were performed and a solid cement spacer with gentamicin and vancomycin impregnated was shaped to occupy the remaining space (fig. 2).

In 2011, after achieving complete clinical and biological remission of the infection, the cement spacer was removed and LCCK revision prosthesis was inserted (fig. 3).

In 2013 reinfection occurred leading to removal of the prosthetic implants and reinsertion of an antibiotic impregnated cement spacer.
Since the patient suffered significant bone loss and the local conditions were unfavorable, being prone to infection, there were 2 options to evaluate: knee arthrodesis or above knee amputation. We chose knee arthrodesis using Ilizarov external fixation technique (fig. 4).

\section{Results}

After surgery, we achieved complete contact between the tibial and femoral surfaces, having a loss of 4 centimeters of the limb length. The operating time was 5 hours, which is a little bit longer as reported by other authors (4.1 according to Conway and colleagues) [8].

Complications that may occur as described in literature: infection at the wire and halfpin insertion sites, loosening of transosseous elements, overload fracture, loss of sensitivity around the knee, soft tissue infection, ankle ankylosis, genu recurvatum. We encountered infection at the wire and half-pin sites which was treated with topic antibiotherapy and dressing change.

Complete bone fusion was gained in 12 
months (fig. 5). We removed the frame after plain radiographs showed good contact of the bone surfaces and a clinical stress test showed good mechanical stability. The patient could fully bear weight without crutches or any canes when the frame was removed. The patient was educated to wear a knee brace all the time (day and night), tacking it off only for hygiene.

Follow-up was for 36 months, with stages at 2 and 4 weeks after surgery and after that on a monthly basis; each clinical evaluation included knee radiographs to assess the bone surfaces contact. At the time of the frame removal there was a shortening of the limb of 4 centimeters, which was comparable with the mean shortening reported by other authors $(2,5-6,4 \mathrm{~cm})[3,5,10,29,31,32]$.

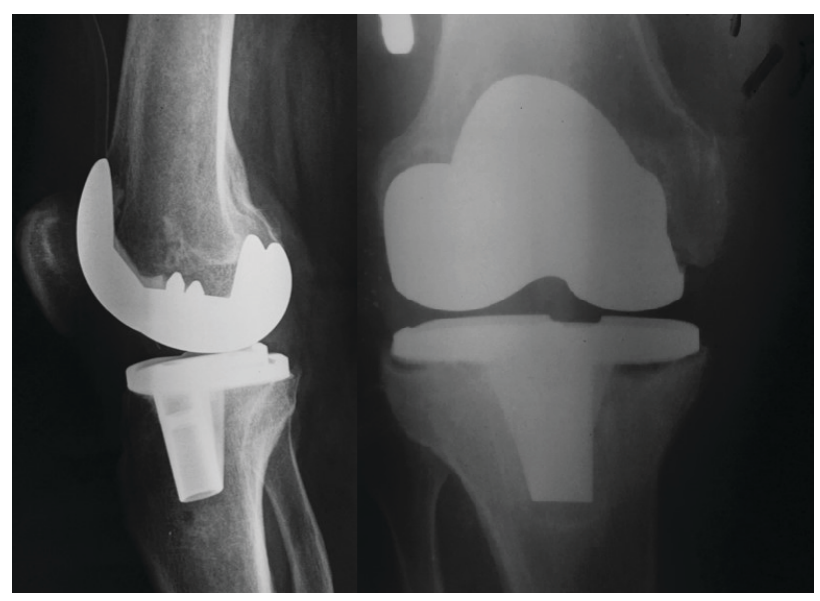

Fig. 11 year postop follow-up septic TKA

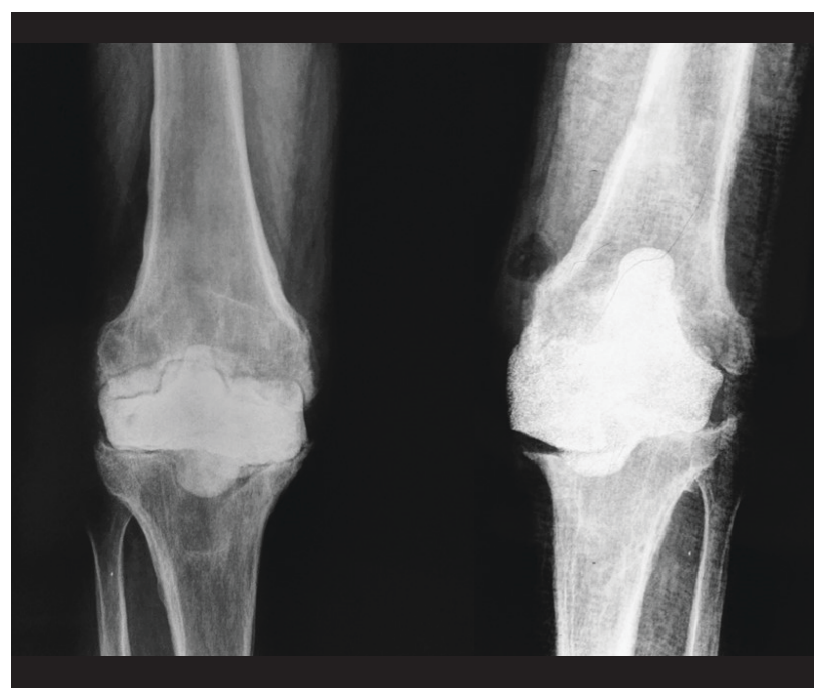

Fig. 2 Cement spacer - replacement for the septic TKA

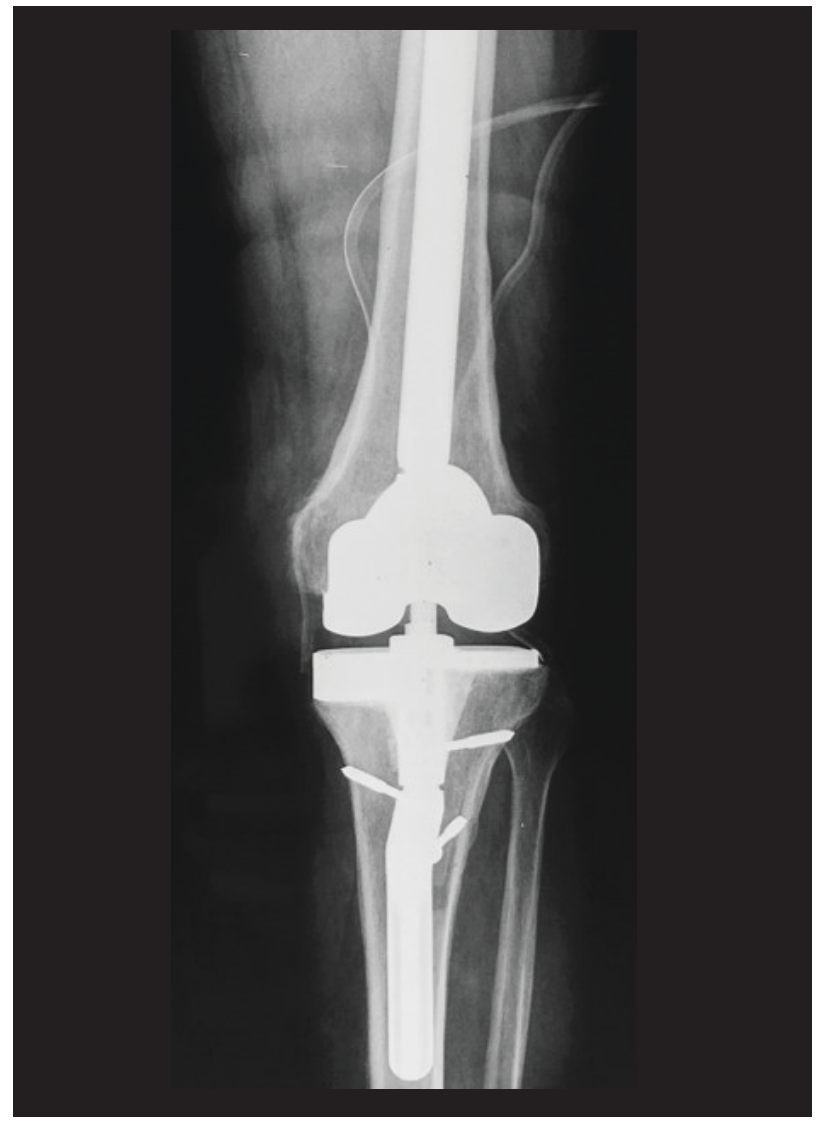

Fig. 3 LCCK revision prosthesis

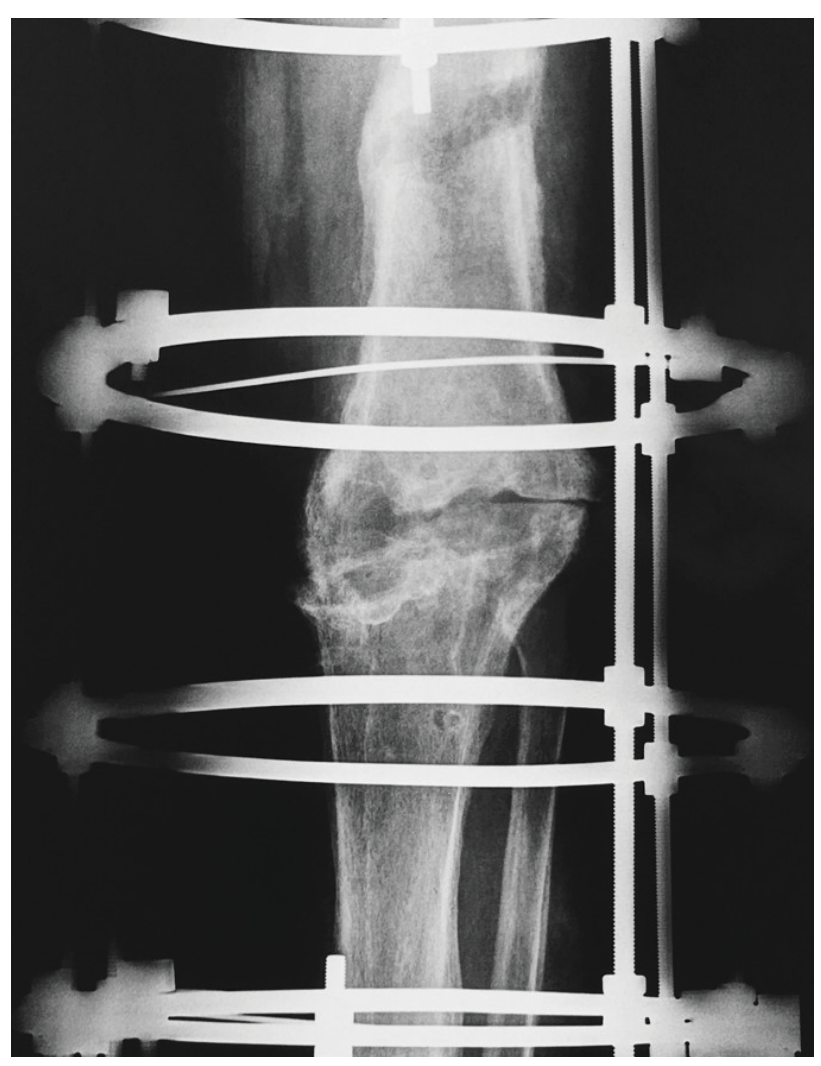

Fig. 4 PostopX-Ray knee arthrodesis using Ilizarov external fixation technique 

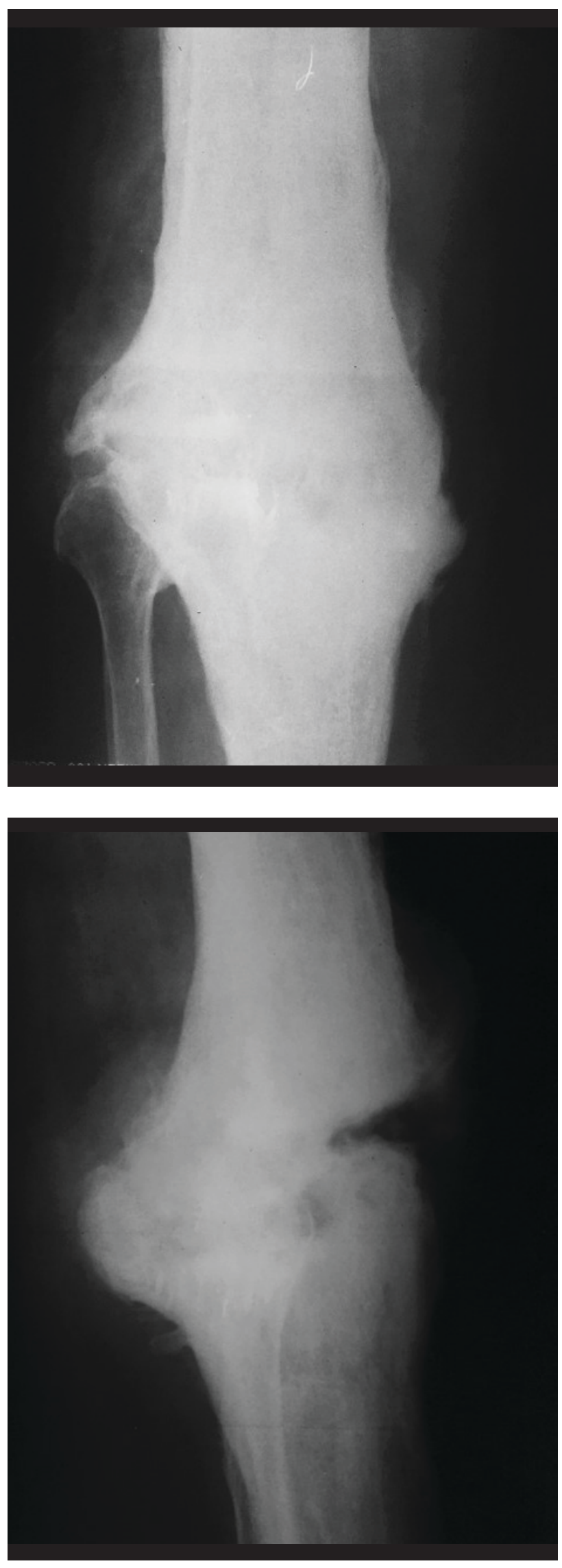

Fig. 51 year follow-up after the removal of llizarov frame showing complete bone fusion

\section{Discussion}

Knee arthrodesis represents a viable treatment option for patients with septic TKA for which other treatment options did not work.

Increased interest in this salvage technique of the affected pelvic limb has generated numerous research studies that ultimately concluded that in order to achieve a good bone fusion, it is necessary to have a very good bone contact between the femur and the tibia $[8,19,24,42]$, a firm fixation $[36,42]$, and a lesser area of bone loss $[29,33]$.

Intramedullary nailing is the best treatment procedure for knee arthrodesis, achieving a consolidation rate of $67-100 \%[1,2,9,11,12$ $14,22-25,27,28,30,32,37,41,42]$. However, there are limitations in the use of this technique, mainly represented by the existence and persistence of the bone infection. In these cases, the use of the intramedullary nailing is not recommended, as complications such as dissemination or reactivation of the infection may occur [24].

Other complications that may occur in $40-55 \%$ cases $[25,42,43]$ are nail migration into the bone canal, distal tibial fractures, pseudarthrosis, vascular-nerve lesions, rotational defects.

In cases of resistant infection, external fixation represents a viable alternative to intramedullary nailing, having a significant contribution to the healing of the infectious outbreak and achieving a consolidation rate of 43-100\% [10,18-20,26,29,34,35]. Reported external fixation complications are less important from a biomechanical and clinical point of view, but may be: pin/ wire infections, long-term treatment time, frame maintenance and cosmetic appearance $[5-7,16,17,19,36,38$ 40,42].

Hak and colleagues demonstrated that there were better results when using the multiplanar fixators [20].

Plates are less used, very few cases reported, due to the fact that this treatment 
method does not provide compression during weight bearing unfavorable effects on bone consolidation $[9,30,41]$.

llizarov circular frame is an important therapeutic option for knee arthrodesis due to the fact that it stimulates bone formation and it improves the bone quality by progressive compression and distraction in the arthrodesis site [29,31]. This device also allows a good alignment of the bone segments through the proper use of the pins. Obtaining bone fusion when using llizarov external fixator in patients with bone defects is described by some studies as being between $93-100 \%$, unlike other types of external fixators $[10,29,31,42]$.

The rate of bone fusion may be influenced by both the number of surgical interventions and the type of microorganism involved in TKA infection. Damron and McBeath concluded in their study that patients with mixed infections and those with Gram negative bacteria have a much lower bone fusion rate [9]. In another review study, Hanssen reported an average of 13 surgical interventions before knee arthrodesis has been performed, all these surgical procedures having a negative impact in bone quality [21].

\section{Conclusions}

Many surgical techniques are available to achieve knee arthrodesis: internal fixation with plates or intramedullary nails and external fixation. The llizarov frame provides a mechanical stimulus for bone formation without the need for bone grafts. The llizarov method is a very effective technique that could be taken into consideration when knee arthrodesis is required.

\section{Conflict of Interest statements}

Authors state no conflict of interest.
Informed Consent and Human and Animal Rights statements

Informed consent has been obtained from all individuals included in this study.

\section{Authorization for the use of human subjects}

Ethical approval: The research related to human use complies with all the relevant national regulations, institutional policies, is in accordance with the tenets of the Helsinki Declaration, and has been approved by the authors' institutional review board or equivalent commitee.

\section{References}

1. Arroyo JS, Garvin KL, Neff JR. Arthrodesis of the knee with a modular titanium intramedullary nail. J Bone Joint Surg Am. Jan 1997; 79(1):26-35.

2. Bargiotas K, Wohlrab D, Sewecke JJ, Lavinge G, Demeo PJ, Sotereanos NG. Arthrodesis of the knee with a long intramedullary nail following the failure of a totalknee arthroplasty as the result of infection. J Bone Joint Surg Am Mar. 2006; 88(3):553-8.

3. Behr JT, Chmell SJ, Schwartz CM. Knee arthrodesis for failed total knee arthroplasty. Arch Surg. Mar 1985; 120(3):350-4.

4. Bengst Typesetteron S, Knutson K, Lidgren L. Treatment of infected knee arthroplasty. Clin Orthop Relat Res. Aug 1989; 245:173-8.

5. Brodersen MP, Fitzgerald RH Jr., Peterson LF, Coventry MB, Bryan RS. Arthrodesis of the knee following failed total knee arthroplasty. J Bone Joint Surg Am. Mar 1979; 61(2):181-5.

6. Charnley J, Baker SL. Compression arthrodesis of the knee; a clinical and histological study. J Bone Joint Surg Br. May 1952; 34-B(2):187-99.

7. Christie MJ, DeBoer DK, McQueen DA, Cooke FW, Hahn DL. Salvage procedures for failed total knee arthroplasty. J Bone Joint Surg Am. 2003; 85-A(Suppl. 1):S58-62.

8. Conway JD, Mont MA, Bezwada HP. Arthrodesis of the knee. J Bone Joint Surg Am. Apr 2004; 86-A(4):835-48.

9. Damron TA, McBeath AA. Arthrodesis following failed total knee arthroplasty: comprehensive review and meta-analysis of recent literature. Orthopedics. Apr 1995; 18(4):361-8.

10. David R, Shtarker H, Horesh Z, Tsur A, Soudry M. Arthrodesis with the Ilizarov device after failed knee arthroplasty. Orthopedics. Jan 2001; 24(1):33-6.

11. Donley BG, Matthews LS, Kaufer H. Arthrodesis of the knee with an intramedullary nail. J Bone Joint Surg Am. 
Jul 1991; 73(6):907-13.

12. Ellingsen DE, Rand JA. Intramedullary arthrodesis of the knee after failed total knee arthroplasty. J Bone Joint Surg Am. Jun 1994; 76(6):870-7.

13. Fern ED, Stewart HD, Newton G. Curved Kuntscher nail arthrodesis after failure of knee replacement. J Bone Joint Surg Br. Aug 1989; 71(4):588-90.

14. Ferrone JD, Donaldson WR. Advantages of the long intramedullary rod for arthrodesis of the knee. Comp Orthop. 1996; 11:19-23.

15. Fidler MW. Knee arthrodesis following prosthesis removal. Use of the Wagner apparatus. J Bone Joint Surg Br. Jan 1983; 65(1):29-31.

16. Figgie HE 3rd, Brody GA, Inglis AE, Sculco TP, Goldberg VM, Figgie MP. Knee arthrodesis following total knee arthroplasty in rheumatoid arthritis. Clin Orthop Relat Res. Nov 1987; 224:237-43.

17. Frymoyer JW, Hoaglund FT. The role of arthrodesis in reconstruction of the knee. Clin Orthop Relat Res. Jun 1974; 101:82-92.

18. Garberina MJ, Fitch RD, Hoffmann ED, Hardaker WT, Vail TP, Scully SP. Knee arthrodesis with circular external fixation. Clin Orthop Relat Res. Jan 2001; 382:168-78.

19. Green SA, Kolsnick R. Arthrodesis of the knee. Orthopedics. Dec 1985; 8(12):1514-8.

20. Hak DJ, Lieberman JR, Finerman GA. Single plane and biplane external fixators for knee arthrodesis. Clin Orthop Relat Res. Jul 1995; 316:134-44.

21. Hanssen AD, Trousdale RT, Osmon DR. Patient outcome with reinfection following reimplantation for the infected total knee arthroplasty. Clin Orthop Relat Res. Dec 1995; 321:55-67.

22. Harris CM, Froehlich J. Knee fusion with intramedullary rods for failed total knee arthroplasty. Clin Orthop Relat Res. Jul-Aug 1985; 197:209-16.

23. Incavo SJ, Lilly JW, Bartlett CS, Churchill DL. Arthrodesis of the knee: experience with intramedullary nailing. J Arthroplasty. Oct 2000; 15(7):871-6.

24. Klinger HM, Spahn G, Schultz W, Baums MH. Arthrodesis of the knee after failed infected total knee arthroplasty. Knee Surg Sports Traumatol Arthrosc. May 2006; 14(5):447-53.

25. Knutson K, Hovelius L, Lindstrand A, Lidgren L. Arthrodesis after failed knee arthroplasty. A nationwide multicenter investigation of 91 cases. Clin Orthop Relat Res. Dec 1984; 191:202-11.

26. Knutson K, Bodelind B, Lidgren L. Stability of external fixators used for knee arthrodesis after failed knee arthroplasty. Clin Orthop Relat Res. Jun 1984; 186:90-5.

27. Lai KA, Shen WJ, Yang CY. Arthrodesis with a short Huckstep nail as a salvage procedure for failed total knee arthroplasty. J Bone Joint Surg Am. Mar 1998; 80(3):380-8.

28. Mabry TM, Jacofsky DJ, Haidukewych GJ, Hanssen AD. Comparison of intramedullary nailing and external fixation knee arthrodesis for the infected knee replacement. Clin Orthop Relat Res. Nov 2007; 464:115.
29. Manzotti A, Pullen C, Deromedis B, Catagni MA. Knee arthrodesis after infected total knee arthroplasty using the Ilizarov method. Clin Orthop Relat Res. Aug 2001; 389:143-9.

30. Nichols SJ, Landon GC, Tullos HS. Arthrodesis with dual plates after failed total knee arthroplasty. J Bone Joint Surg Am. Aug 1991; 73(7):1020-4.

31. Oostenbroek HJ, van Roermund PM. Arthrodesis of the knee after an infected arthroplasty using the Ilizarov method. J Bone Joint Surg Br. Jan 2001; 83(1):50-4.

32. Puranen J, Kortelainen P, Jalovaara P. Arthrodesis of the knee with intramedullary nail fixation. J Bone Joint Surg Am. Mar 1990; 72(3):433-42.

33. Rand JA, Bryan RS, Morrey BF, Westholm F. Management of infected total knee arthroplasty. Clin Orthop Relat Res. Apr 1986; 205:75-85.

34. Rand JA, Bryan RS, Chao EY. Failed total knee arthroplasty treated by arthrodesis of the knee using the Ace-Fischer apparatus. J Bone Joint Surg Am. Jan 1987; 69(1):39-45.

35. Rand JA. Alternatives to reimplantation for salvage of the total knee arthroplasty complicated by infection. J Bone Joint Surg Am. Feb 1993; 75(2):282-9.

36. Rothacker GW Jr., Cabanela ME. External fixation for arthrodesis of the knee and ankle. Clin Orthop Relat Res. Nov 1983; 180:101-8.

37. Senior CJ, da Assunção RE, Barlow IW. Knee arthrodesis for limb salvage with an intramedullary coupled nail. Arch Orthop Trauma Surg. Jul 2008; 128(7):683-7.

38. Spina M, Gualdrini G, Fosco M, Giunti A. Knee arthrodesis with the Ilizarov external fixator as treatment for septic failure of knee arthroplasty. J Orthop Traumatol. Jun 2010; 11(2):81-8.

39. Stulberg SD. Arthrodesis in failed total knee replacements. Orthop Clin North Am. Jan 1982; 13(1):213-24.

40. Thornhill TS, Dalziel RW, Sledge CB. Alternatives to arthrodesis for the failed total knee arthroplasty. Clin Orthop Relat Res. Oct 1982; 170:131-40.

41. Waldman BJ, Mont MA, Payman KR, Freiberg AA, Windsor RE, Sculco TP et al. Infected total knee arthroplasty treated with arthrodesis using a modular nail. Clin Orthop Relat Res. Oct 1999; 367:230-7.

42. Wiedel JD. Salvage of infected total knee fusion: the last option. Clin Orthop Relat Res. Nov 2002; 404:139-42.

43. Wilde $\mathrm{AH}$, Stearns KL. Intramedullary fixation for arthrodesis of the knee after infected total knee arthroplasty. Clin Orthop Relat Res. Nov 1989; 248:8792. 